\title{
Study on Plastic Arts of Jintan Paper-carving
}

\author{
Lei Zhang $^{1}$ \\ ${ }^{1}$ Institute of Architecture Decoration, Changzhou Vocational Institute of Engineering, Changzhou, \\ Jiangsu, 213164
}

KEYWORDS: Paper-carving; The Plastic Arts; Engraved Paper Artist; Engraved Paper Works;

\begin{abstract}
Jintan is always cultural atmosphere, Paper - carving is Chinese folk arts and crafts in a field of brilliant flowers. This paper describes the Zhu Xiaokun, Yan zhuoning, Sub Rongcaicai, Yang Zhao and other groups 4 Paper - carving everyone's creative techniques and work style characteristics. A selection of "Math Fest Hua Luogeng", "From Athens to Beijing" and two representatives of Paper - carving masterpiece are for a more detailed analysis of its performance practices and moral connotations.
\end{abstract}

\section{Introduction}

Xue Town from the east village to explore and investigate the situation of human monks pier remains of Paleolithic culture processing field of view, about 50 million years ago, the altar area of ancient stone carvings of human and scraping appliance has a lot of this from a reflection of the golden altar carved ancient human level. Samsung gold altar unearthed from the ruins of the village of six thousand years ago and the plate engravings silkworm totem bone proving once again that the region's art and culture carved and engraved paper long.

\section{Paper-carving}

Jintan honest, cultural blend is known as "Jiang blessed land" reputation, the Ministry of Culture Qinshou "Chinese folk paper cut arts village." Paper - carving a long historical origins, precious artistic value, rich regional characteristics, profound cultural impact, which in 199312 menstrual Jiangsu Provincial People's Government, became the first provincial intangible cultural heritage, in June 2008 and was approved by the State Council for the second batch of national intangible cultural heritage. At this meeting, as "Chinese paper-cut," an important part of the carving in the paper was selected as intangible cultural heritage list. China's scissors cut paper art "North South show male", the golden altar engraved paper compared with paper-cut north, more rich and refined show, known as "Jiangnan a flower." After many years of tradition and innovation development, has formed a paper carving in more than 600 sub-types, the performance of a wide range, rich in content, most auspicious, contains folk. Compared with other art forms of the same type, Paper carving show-spoke more flexible and creative approach more diverse, engraving works out fine, delicate, with distinct characteristics of Yangtze River Delta region and strong traditional culture flavor , at home and abroad who love and praise.

\section{Paper - carving Artist}

Zhu Xiaokun, Yin Zhuoning, Sun Rongcai are individually as Paper - carving in the old, the young representatives of three generations. This trio in 1995, the same batch by UNESCO awarded the "Chinese Folk Arts and Crafts" title. 
Zhu Xiaokun line drawing good modeling ability, but also more interested in historical themes, especially worship poet $\mathrm{Li} \mathrm{Bai}$ and $\mathrm{Tu} \mathrm{Fu}$, so when he was appointed executive director of the Association under the paper-cut proposal Zhou Yunhua, began the creation of the four poets engraved paper . Preliminary like Illustrated and line drawing, paper cutting flavor inadequate, so in reference to some of Ruijin Fu paper-cut works after the modification. Most of these works reflect the history of the story, and have decorative patterns border, paper-cut and distinctive features. Zhu Xiaokun will fully absorb this form of play and creativity, patterns of vanilla detailed scrutiny and amended several times, completed a set of four very unique four poets engraved paper works. Zhu Xiaokun spent several months repeated study, modify Ren Bo painted "Qunxian birthday map" calendar, the use of point, line and plane, black and white ash composition principle of detailed scrutiny, finally completed the "Immortals birthday chart" The Giant pieces engraved paper drawings. Subsequent Zhu Xiaokun authoring extensive use of this form, which was undoubtedly the most famous "Bedford parallel Zhen," has become a symbol representative of its program of work. "Immortals birthday chart", "Bedford parallel Zhen," these two works called Zhu Xiaokun engraved paper masterpiece.

Yin Zhuoning has since the age of seven will follow the franchise lights, lanterns, dragon father learning engraved paper cut, and engaged in the practice and research of engraved paper. His mastery of skills and deep skill entirely derived from the ancestral art of traditional cut engraved paper, but on the basis of inheriting the tradition, he is more manifestation of the pursuit of innovation. As Paper - carving of representative inheritors and the famous Chinese Folk Arts and Crafts home, Yin Zhuoning to create a unique "empty Cephas," that paper to blow hollow Cephas creation, so that works more three-dimensional sense, this method is engraved in the paper industry had a great response. In order to reproduce the brilliant ancient art, following the hollow Cephas, Yan Zhuoning struggling to explore, bold innovation, in turn had been engraved glass platform hard to soft engraved. Not only that, he has to cut, cut, tear and other techniques as well as trapping, point blank, dyeing and other forms greatly enriched the paint color etching method, not only reduces the difficulty of engraving, creation of improved efficiency, but also to make the work more sophisticated. Yan Zhuoning been advocated engraved paper and painting combine Interworking, engraved paper is actually absorbed painting, prints, paintings and other decorative painting art form is characterized, on curved, straight, sharp lines reflect its own plastic arts language. Yan Zhuoning engraved paper mainly works on behalf of "three thousand drums rap", "From Athens to Beijing", "Hail Expo", "Five Blessings", "Fortune" and so on.

Sub Rongcaicai was born in Jintan rural childhood love of painting. His grandmother and mother cut a good hand like shoes and grilles, by their influence, Sub Rongcai was carved from the urine of folk art of paper generated strong interest. During 1973, the Shaanxi army learned paper cutting, paper-cut rough outline of the northwest brought his heroic style influence of the arts. After the war, Sub Rongcai served 11 years in the cultural center owners, he devote himself to the creation of engraved paper during the 11 years he created has become a "golden period." In the older generation to the Shaanxi paper-cut artists while studying Sub Rongcai often only learn the advantages of other parts of the scissors cut paper art, absorbing, into their own works of creation, its original Shredded Art is a must. Sub Rongcai works simple composition, smooth lines, exaggerated and yet coordinated, brimming with rich golden altar geographical characteristics. "100 Mito", "courtyard", "Chinese Olympic dream soul" and a number of far-reaching influence in the country engraved paper industry. The international community has a considerable reputation for fine engraved paper are his masterpiece. Sub Rongcai was creative expertise lies in the performance of the theme of rural life, his "barnyard", "Cai Ling map", "sugarcane harvest" and other works, 
vivid images, which fully reflects the reform and opening up to the liberation of southern rural productivity brought about by the economic development and commercial prosperity. The "Younger", "Pastoral", "courtyard" and a series of works, letting the audience really feel contemporary farmers new mental outlook. Sub Rongcai was engraved paper work, rough style, bold, earthy fragrance gives aesthetic pleasure.

Yang Zhao group is a third batch of national intangible cultural heritage items (Paper - carving) representative inheritors. He has long been influenced by his father, a child will engage in cut, engraved paper creation, in the tradition of engraved paper presentation style basis, into the very characteristics of modern innovation. Yang Zhao engraved paper group works mostly contemporary life as the performance of the theme, new forms, composition exquisite, elegant style, flowing lines and simple image of an exaggeration. He was particularly good at the moment, just outside the soft works fine blade frustrated. Inheritance and he will appreciate the contemporary life of folk art were organic integration, so long tradition and contemporary pop art style engraved paper works to achieve a near-perfect combination. "Magpie Bridge", "full steam ahead", "Harvest of Joy", "From Athens to Beijing", which are groups of Yang Zhao engraved paper representative works.

\section{Paper-carving Works}

To commemorate the 100th anniversary of the birth of the famous mathematician Hua, Sub Rongcai by the teachers and the creation of cooperation and Jintan Shetou Central Primary School completed a piece of paper - cutting works, the whole picture magnificent momentum and delicate composition impressive. Hollow window frame coupled with sunflower disk, exquisite, old Chinese expression serene, sit them. His famous "hard work and practice is a lifelong thing," which is located directly below a picture book. Background bamboo symbolizes the lofty spirit of old China, and the foreground pine bonsai bloom tirelessly on behalf of his character. Whole is engraved paper work called talent and profound meaning.

From Athens to Beijing" by Yang Zhao group in October 2004 began the creative, and brings together Yin Zhuoning, Tan Weiping, She Yunxiang, Liu, five folk artists engraved paper in his spare time co-authoring is complete. To complete the high quality painting, Yang Zhao group held several countries and cities went to inspect the Olympic Games in Athens, London, Barcelona and Sydney history. During the shooting a lot of photos, a collection of numerous data, and repeatedly discussed with the members of the creative team, modify, which lasted more than three years, was finally completed in December 2007. Works with "Olympic epic, world harmony" as the theme, 29 meters long, 2.008 meters wide, meaning 2008, the 29th Summer Olympic Games. In the previous screen hosted the Summer Olympics in 18 countries, 22 the city's iconic buildings, the previous Summer Games gold medal and mascot, eight IOC president and head of the 29th Beijing Olympic Games all events and other content to be reproduced in the form of art. It works vividly show from the first modern Olympics in Athens in 1896 until the beginning of the 2008 Beijing Olympic Games history and culture of each contractor, special scenery, local customs, culture and customs of the city and so on. 2008 dove of peace interspersed dotted among the picture, vividly demonstrated the brilliant history of the Olympic Games, the Olympic Games and the richness of cultural heritage of the whole world. "From Athens to Beijing" has been the National Museum "national collection" status of the collection. National Museum of cultural relics collection experts have been dedicated to the golden altar issued collection certificate to Yang Zhao and other groups, the experts commented, "From Athens to Beijing": "works full of rich Chinese culture, standing on the perspective of the oriental culture to resolve the Olympic Movement, and explore fusion point international Olympic spirit and Chinese folk culture and ideology. "painting called all the 
Olympics as a unique genre engraved paper boutique, its extraordinary artistic expression so that it deserved to become the world's paper-cut masterpiece. [5] (Figure 2)
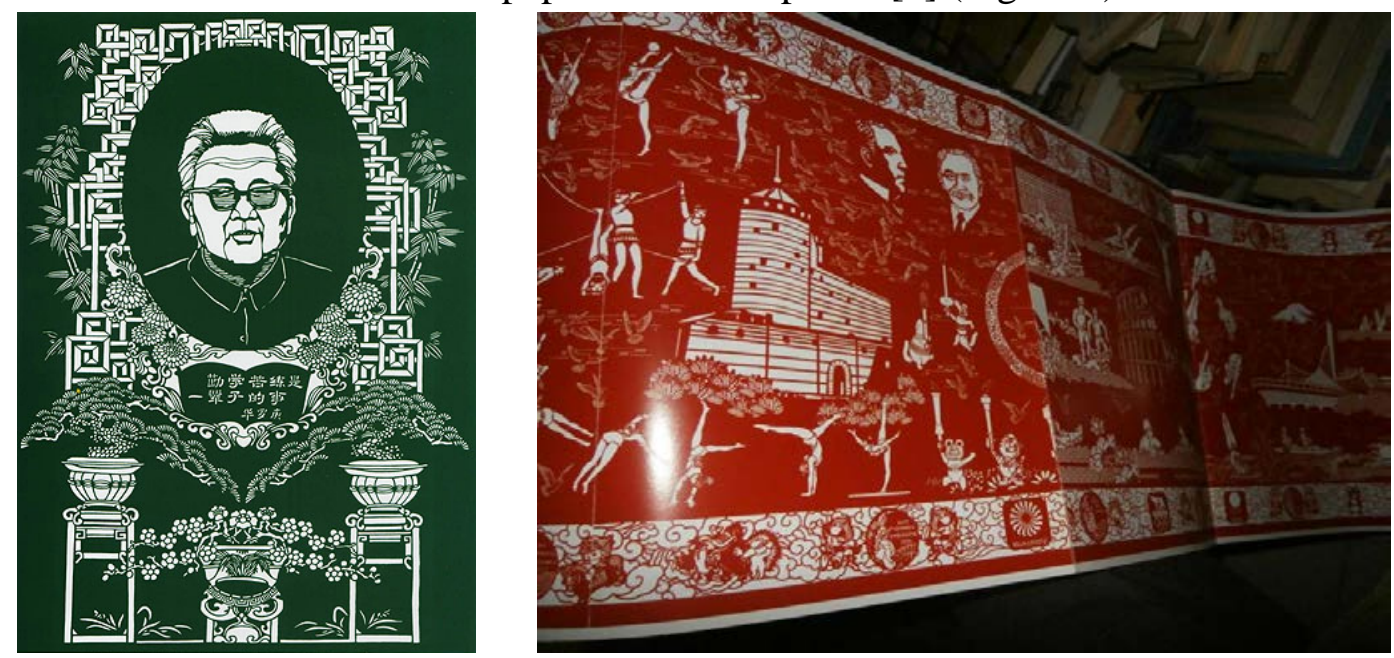

Figure 1: The "Math Superstar Hua" Figure 2: "From Athens to Beijing"

\section{Conclusion}

From the context of the development of art of paper cutting, you can clearly see the folk paper-cut vitality. Understand the history of folk paper-cut, study its survival situation, its future prospects in order to regenerate. Adhere to the heritage of traditional paper-cut art form, language, and then change its stylish and interesting, is the key to success in modern folk paper-cut towards transformation. Paper - carving the classic folk art treasures, is not only a golden altar of wealth, it is the pride of the whole China. As an important part of China's intangible cultural heritage, carving in paper alone with lofty ideals will spread more widely its modeling language out, but look forward to many more people can understand and appreciate its artistic charm.

\section{Acknowledgement}

Project: Partial Research Achievements, Jiangsu Provincial Department of Education 2015 Social Science Project "Changzhou traditional arts heritage resources in applied research in the cultural building of the university" (fund mentoring programs). Project No.: 2015SJD541.

2015 annual Jiangsu Provincial Department of Education Reform of Higher Education in Jiangsu Province project topics (general issue) part of the research results "Art and Design Creative Talents Local Culture Background Practices", Project No.: 2015JSJG529.

Steering Committee, Ministry of Education, Vocational College Cultural Quality Education 2015 annual education research project "Practice of the Colleges of Arts elective curriculum development based on heritage education - 'Traditional Folk Plastic Arts Appreciation' courses as an example" (general issue) part of the research results. Project No.: WH125YB58.

\section{REFERENCE:}

[1] Zuo Hanzhong. Chinese Folk Art Form (Revised) [M]. Changsha: Hunan Fine Arts Publishing House, 2012: 285.

[2] Qian Xiangdong. Jiangsu paper-cut [J]. decorative .2001,44 (4): 17. 
[3] Pan Lusheng, Lei Hongmiao. paper-cut [M]. Beijing: China Social Sciences Publishing House, 2008: 2.

[4] Xu Zuliang splendid Chinese Folk Art Flower - read "Paper - carving" [J]. Hundred Schools In Art .2004,6 (3): 112-113.

[5] Gao Hong. research Hong Protective Development Strategy Paper - carving art [J]. Huanggang Vocational and Technical College .2011,2 (1): 54-57.

[6] Chen Qing. Shear - Native art of urban regeneration [J]. public art .2012,4 (1): 44-49. 